Article

\title{
Time-Resolved Tomographic Quantification of the Microstructural Evolution of Ice Cream
}

\author{
Jingyi Mo ${ }^{1,2, *}$, Enyu Guo ${ }^{3}{ }^{(0)}$, D. Graham McCartney 1,2® ${ }^{1}$, David S. Eastwood ${ }^{2,4}$, Julian Bent ${ }^{5}$, \\ Gerard Van Dalen ${ }^{5}$, Peter Schuetz ${ }^{5}$, Peter Rockett ${ }^{1}$ and Peter D. Lee ${ }^{1,2, *(D)}$ \\ 1 Department of Mechanical Engineering, University College London, London WC1E 7JE, UK; \\ graham.mccartney@nottingham.ac.uk (D.G.M.); peterrockett33@gmail.com (P.R.) \\ 2 Research Complex at Harwell, RAL, Didcot OX11 0FA, UK; david.eastwood@manchester.ac.uk \\ 3 School of Materials Science and Engineering, Dalian University of Technology, Dalian 116024, China; \\ eyguo@dlut.edu.cn \\ 4 The Manchester X-ray Imaging Facility, School of Materials, The University of Manchester, \\ Manchester M13 9PL, UK \\ $5 \quad$ Unilever R\&D, Colworth MK44 1LQ, UK; Julian.Bent@unilever.com (J.B.); \\ Gerard-van.Dalen@unilever.com (G.V.D.); Peter.Schuetz@unilever.com (P.S.) \\ * Correspondence: j.mo@ucl.ac.uk (J.M.); peter.lee@ucl.ac.uk (P.D.L.)
}

Received: 10 September 2018; Accepted: 15 October 2018; Published: 19 October 2018

\begin{abstract}
Ice cream is a complex multi-phase colloidal soft-solid and its three-dimensional microstructure plays a critical role in determining the oral sensory experience or mouthfeel. Using in-line phase contrast synchrotron X-ray tomography, we capture the rapid evolution of the ice cream microstructure during heat shock conditions in situ and operando, on a time scale of minutes. The further evolution of the ice cream microstructure during storage and abuse was captured using ex situ tomography on a time scale of days. The morphology of the ice crystals and unfrozen matrix during these thermal cycles was quantified as an indicator for the texture and oral sensory perception. Our results reveal that the coarsening is due to both Ostwald ripening and physical agglomeration, enhancing our understanding of the microstructural evolution of ice cream during both manufacturing and storage. The microstructural evolution of this complex material was quantified, providing new insights into the behavior of soft-solids and semi-solids, including many foodstuffs, and invaluable data to both inform and validate models of their processing.
\end{abstract}

Keywords: ice cream; microstructure; tomography; ice crystals; coarsening; soft solids

\section{Introduction}

Ice cream is a widely consumed dairy product whose complex microstructure determines its texture and oral sensory perception. The main constituents of ice cream are air cells, ice crystals, finely dispersed (emulsified) fat globules, and a continuous unfrozen aqueous solution phase (containing sugars and other additives) and, as shown in Figure 1a, the ice crystal fraction varies markedly with temperature. Ice cream is known to have a complex microstructure which is a function of its formulation but also its thermal history during manufacture, storage, and handling. An important aim of any manufacturer is to ensure their process produces ice cream with a smooth texture which does not degrade to a grainy and coarse texture before the product is consumed and enjoyed. The size of the ice crystals is widely recognized to be a key factor in the perception of texture by consumers; larger crystals being, in general, undesirable [1].

It is thus crucial to be able to observe how the complex three-dimensional structure of ice cream evolves over time with changes in temperature. The traditional method of examination using 
cryo-SEM of extracted samples (Figure 1b) is capable of providing excellent spatial resolution. However, the contrast between the different phases can be limited and only a two-dimension image is captured of the complex three dimensional (3D) interconnected network of air cells, ice crystals, and unfrozen matrix. During the past decade, there has been a significant increase in the use of synchrotron computed tomography ( $\mathrm{sCT}$ ) to examine the evolution of structures over time in three dimensions as the temperature is changed (termed $4 \mathrm{D}, 3 \mathrm{D}$ plus time, tomography) and so $\mathrm{sCT}$ is, in principle, well suited to the study of ice cream microstructures. Indeed, very recent studies have demonstrated the power of 3D sCT for studying the complex microstructure of ice cream; Figure 1c,d. sCT permits quantitative measurements of different phases and allows the visualization of 3D connectivity.

In the present paper, we will describe the application of $4 \mathrm{D} \mathrm{sCT}$ to reveal the microstructural evolution in ice cream over a range of different timescales, namely that which takes place during the manufacturing process (short timescales, minutes) and storage over long timescales (days/weeks). We apply in situ, time-resolved $\mathrm{sCT}$ to reveal the microstructure evolution mechanisms during manufacturing; whereas we use an ex situ sCT methodology to provide time-resolved data during long-term ice cream storage.
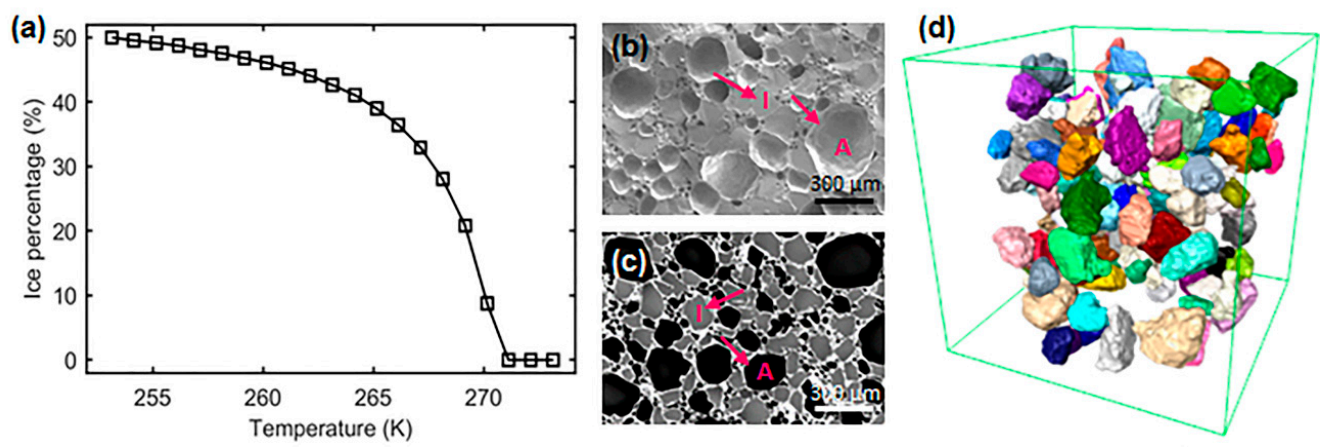

Figure 1. The characteristics of ice crystals in ice cream samples: (a) ice crystal volume fraction as a function of temperature; (b) a typical cryo-SEM image, showing air cells, A, and ice crystals, I; (c) 2D $\mathrm{X}$-ray tomographic image of an ice cream sample. Note, the contrast was enhanced via edge-constrained diffusion filtering (300 iterations). Dark features are air cells, grey features are ice crystals and white regions are the unfrozen matrix; (d) 3D renderings of the ice crystals from $X$-ray tomographic images, providing a 3D view of the features. Here, the ice crystals are individually color rendered (after Reference [2]).

The manufacturing process for ice cream introduces around $50 \mathrm{vol} \%$ of air cells so the typical make up of frozen ice cream, by volume, is $50 \%$ air cells, $30 \%$ ice crystals, $10-15 \%$ sugar solution matrix and the balance dispersed fat droplets and non-fat solids [1,3]. Ice cream is commonly manufactured in a scraped-surface freezer (SSF) in either a batch or continuous mode as described, for example, in Cook and Hartel and others [4-8]. The initial processes occurring in the SSF are likely to be the most important in determining ice crystal size and size distribution. In a typical SSF, the mix is rapidly cooled at the wall of a highly chilled cylindrical barrel and ice crystals nucleate and grow at, or close to, the wall and potentially into an undercooled liquid [9]. Rotating scraper blades break up the initially formed crystals and sweep them into the bulk of the mix (where the mean temperature is closer to $269 \mathrm{~K}$ to $267 \mathrm{~K}$ ) causing the fragmentation and partial melting of the initial ice crystals. This process has clear similarities to the metallurgical process known as rheocasting or thixocasting [10]. At the exit of the SSF, about $50 \%$ of the water is frozen and the mix is cooled to about $267 \mathrm{~K}$. The semi-solid product is typically pumped into a container for supply to the consumer and hardened in an air blast freezer. It is cooled to around $255 \mathrm{~K}$ over a period of around $120 \mathrm{~min}(0.1 \mathrm{~K} / \mathrm{min})$ [9] and then stored at or below this temperature. Ideally, the ice crystals will be kept as small as possible at the exit from the SSF but as the temperature drops in the freezer the original ice crystals grow and their volume fraction increases (Figure 1a). 
The texture and sensorial quality of ice cream are related to the size and connectivity of the air cells and ice crystals $[1,11,12]$. It is reported that the microstructural features vary in size considerably with typical values being air cells $20-150 \mu \mathrm{m}$, ice crystals $10-75 \mu \mathrm{m}$, fat globules $\sim 0.5 \mu \mathrm{m}$ with the unfrozen matrix phase being a continuous matrix [9]. Once ice cream is distributed to consumers it can undergo significant temperature variations typically in the range $258 \mathrm{~K}$ to $268 \mathrm{~K}$ and these will affect the ice crystal size and hence perceived texture [7]. Empirically, it is found that long-term storage above $258 \mathrm{~K}$ and/or thermal cycling degrades the ice cream's quality due to coarsening of ice crystals and air cells. Below about $243 \mathrm{~K}$, the matrix phase is transformed to a glass which stabilizes the microstructure but above these temperature, ice crystals are thermodynamically unstable due to the curvature effects and the kinetics of ice crystal coarsening can be quite rapid. The well-known Ostwald ripening phenomenon is a major factor for ice crystal coarsening although other processes such as physical agglomeration also affect the size distribution. Measurements of crystal size distribution have shown that crystal coarsening is very significant in the temperature range of $258 \mathrm{~K}$ to $268 \mathrm{~K}$ and also that temperature oscillations of only around $\pm 1 \mathrm{~K}$ can significantly enhance the coarsening rate [4].

Whilst significant progress has been made in elucidating the process-structure-quality relationships of ice cream, a major limitation is the complex procedures needed to perform microstructural observations by cryo-SEM or transmission electron microscopy (TEM). These are post-mortem techniques [13], and provide only two-dimensional (2D) information on the surface that sliced through the sample [14-17]. Consequently, interpretation of microstructure evolution is subject to assumptions and opens to ambiguity. Recently, X-ray microtomography techniques have been employed to study 3D structures in food products and frozen food, including ice cream, but with somewhat limited success $[7,18,19]$. Pinzer et al. used a laboratory X-ray microCT in a cold room to investigate the long-term microstructural evolution of ice cream and quantified changes in air cell and ice crystal size during thermal cycles between -5 to $-16^{\circ} \mathrm{C}$ over a period of $24 \mathrm{~h}$ [18]. However, the resolution of the structure was a limitation with this instrument.

Ice cream falls into the category of soft solids (of which there are a number found in nature, including food products) and has similar behavior and properties to many man-made and natural semi-solids. The microstructure of many of these materials evolves with time, changing material properties ranging from rheology to yield strength to plasticity, and, in the case of foodstuffs, mouthfeel. One way of quantifying this microstructural evolution is time-resolved radiography $[20,21]$ or tomography [22,23]. Soft solids found in nature include soils [24], shales [25], and magma [26], and food products such as chocolate [27]. In recent years, there has been a growing interest in the use of $4 \mathrm{D}$ tomography, specifically time-resolved synchrotron computed tomography ( $\mathrm{sCT}$ ), to perform non-invasive 3D structure studies of soft solids with high resolution. For example, Kareh et al. used in situ experiments to follow the evolution of semi-solid aluminum alloys under heating and loading conditions [28] whilst Karagadde et al., used in situ indentation to uncover a new fracture mechanism, the transgranular liquation cracking of semi-solid Al-Cu alloys [29].

The use of high brilliance synchrotron X-ray computed tomography ( $\mathrm{sCT}$ ), coupled with a precise cold stage, to study ice cream microstructures has recently been reported by the current authors. In this prior study, we obtained the three-dimensional quantification of microstructural changes arising from the thermal cycling at low heating and cooling rates over periods of weeks. This was undertaken to simulate storage and transport effects on the ice cream product [2]. However, the details of ice crystal development during the manufacturing stages such as those involving processing in a scraped-surface freezer and subsequent slower cooling as a block in an air blast freezer are of great interest but have yet to be studied in detail.

In the present study, we used a bespoke cold stage (capable of controlling the sample temperature precisely between $233 \mathrm{~K}$ and $293 \mathrm{~K}$ with $0.1 \mathrm{~K}$ accuracy) and employed high resolution (in terms of both spatial and contrast) $\mathrm{sCT}$ to conduct $4 \mathrm{D}$ (3D plus time) studies on the microstructural evolution of ice cream samples undergoing different types of thermal histories. In the first set of experiments, the ice cream samples underwent fast heating and cooling cycles to simulate aspects of manufacture and 
were continuously scanned, in situ and operando, during the process. The second set of experiments involved monitoring the microstructural evolution over long timescales and so ex situ experiments could be used to capture the time-dependent evolution. Novel image-based quantification techniques were developed to precisely and robustly evaluate the structural characteristics in the ice cream samples. Variations in the size distribution of ice crystals and unfrozen matrix were followed during the thermal-induced microstructural evolution as these are recognized as indicators for changes in texture and oral sensory perception.

\section{Materials and Methods}

\subsection{Preparation of Ice Cream Samples}

$500 \mathrm{~mL}$ blocks of fresh ice cream containing $5 \%$ fat and $40 \%$ ice were prepared (Unilever R\&D, Colworth, UK). Prior to the in situ tomographic experiments, a block of fresh ice cream was left at room temperature to melt and partially de-aerate. Kapton tubes with $3 \mathrm{~mm}$ inner diameters and $67 \mu \mathrm{m}$ wall thickness (American Durafilm Co. Inc, Holliston, MA, USA) were filled with this liquid dairy mixture using a $5 \mathrm{~mL}$ syringe, followed by mounting them onto a specially designed cold stage which will be described in the next section.

For the ex situ samples, Kapton tubes were inserted into the central region of individual ice cream blocks and the dairy mixture was first subjected to blast freezing at $238 \mathrm{~K}$ and then stored at $248 \mathrm{~K}$. Immediately before observation by synchrotron imaging, the Kapton tubes filled with ice cream were cut from the bulk samples on a dry ice bed (maintained at around $193 \mathrm{~K}$ ) and then inserted into the specially designed cold stage.

\subsection{Cold Stage Experimental Setup and Thermal Cycling for Ex Situ and In Situ sCT}

The cold stage assembly is shown schematically in Figure 2 and described in detail in our previous paper [2]. Both the ex situ and in situ sCT experiments were conducted on beamline I13-2 of the Diamond Light Source (DLS, Harwell, UK) using a pink beam. Details of the beamline set-up are described in the next section.

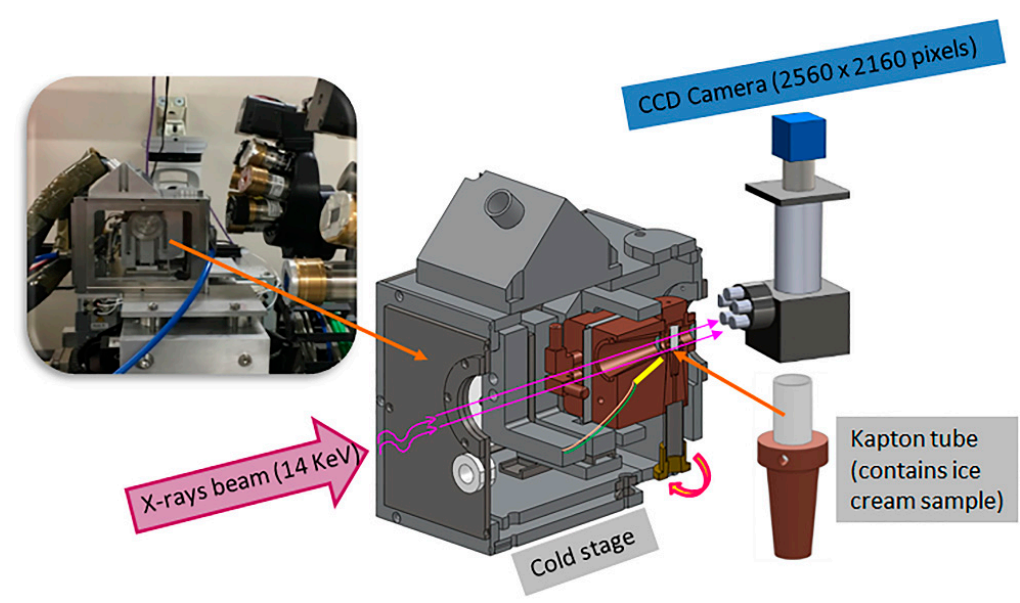

Figure 2. The experimental set-up in beamline I13, Diamond light source. The schematic shows the sectional view of the cold stage, the enlarged inset is the assembly of the ice cream sample, which consists of a $3 \mathrm{~mm}$ Kapton tube and the bottom copper mounts.

In order to investigate processes relevant to the manufacture of ice cream, the in situ thermal cycling experiment was performed following the thermal cycles as described. A Kapton tube containing melted ice cream mixture was firstly mounted into the cold stage at the temperature of $270 \mathrm{~K}$ i.e., just below the melting temperature of the ice cream formulation. It was held at $270 \mathrm{~K}$ for $15 \mathrm{~min}$ and then its temperature was rapidly reduced to $250 \mathrm{~K}$ with a fast rate of cooling of $5 \mathrm{~K} / \mathrm{min}$ (referred 
to as FC) and held at this temperature for $10 \mathrm{~min}$. After that, the sample was heated to $267 \mathrm{~K}$, at a heating rate of $5 \mathrm{~K} / \mathrm{min}$ and held there for $10 \mathrm{~min}$. Subsequently, it was cooled down from this temperature to $250 \mathrm{~K}$ at a slower rate of $0.05 \mathrm{~K} / \mathrm{min}$ (referred to as SC). The overall thermal cycle for in-situ experiments is illustrated in the temperature versus time plot of Figure 3a. The fast cooling (FC) from $270 \mathrm{~K}$ allows one to study the initial ice crystal growth similar to that which might occur near the wall of an SSF. Fast reheating to $267 \mathrm{~K}$ approximates the behavior of ice crystals when swept into the bulk of the SSF. Finally, the SC regime from 267 to $250 \mathrm{~K}$ is regarded as representative of cooling of a block of ice cream mix in a blast freezer.

Blocks of ex situ ice cream samples were cycled between $258 \mathrm{~K}$ and $268 \mathrm{~K}$ multiple times, as shown in Figure 3b. In each daily routine (as shown in Figure 3c), the samples were held at $258 \mathrm{~K}$ for $9.5 \mathrm{~h}$ and then the temperature went up to $268 \mathrm{~K}$ in $2.5 \mathrm{~h}$ (with a rate of $0.067 \mathrm{~K} / \mathrm{min}$ ). After being held at $268 \mathrm{~K}$ for another $9.5 \mathrm{~h}$, the sample temperature cooled back to $258 \mathrm{~K}$ with the same thermal rate $(0.067 \mathrm{~K} / \mathrm{min})$ as before. This 24 -h routine repeated for 7 times over one week (C7) and 14 times over two weeks (C14) before they were scanned using synchrotron X-ray tomography. The sample without any follow-on thermal treatment was referred to as $\mathrm{C} 0$.
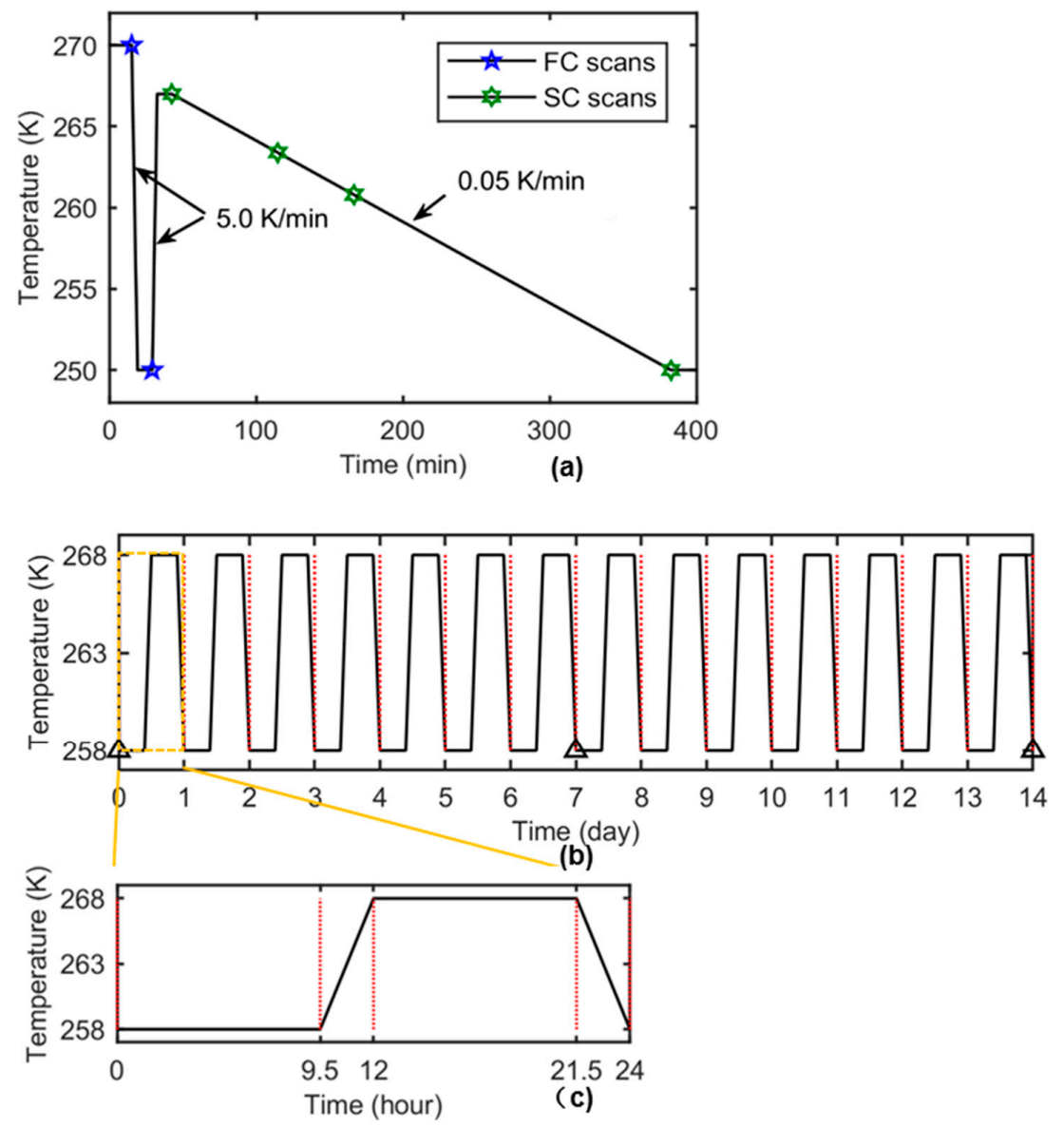

Figure 3. The thermal history of the samples during the in situ and ex situ experiments. (a) The overall thermal history of the in situ ice cream samples; the temperature points where the tomographic scans were reconstructed are indicated as blue pentagon and green hexagon markers. For FC, the images were reconstructed at $270 \mathrm{~K}$ and $250 \mathrm{~K}$ (blue pentagons). For SC, the reconstructed images were obtained at 266.8 K (SC0), $263.4 \mathrm{~K}$ (SC1), $260.8 \mathrm{~K}$ (SC2), and $250 \mathrm{~K}$ (SC3) (green hexagons). The cooling rates for FC and SC are $5.0 \mathrm{~K} / \mathrm{min}$ and $0.05 \mathrm{~K} / \mathrm{min}$, respectively. (b) The overall thermal history of the ex situ ice cream samples, with triangular markers indicating the positions where the ice cream samples were extracted and scanned. (c) The zoom-in thermal profile showing a single ex situ thermal cycle. 


\subsection{Microstructural Characterization Using Synchrotron X-ray Computed Tomography (sCT)}

Concurrently, with the thermal cycling of the sample, a series of X-ray tomographic images were acquired using sCT on I13-2 beamline at Diamond Light Source (Harwell, UK). This has a high flux undulator, producing a pink beam, with peak modes of narrow bandwidth (ca. $300 \mathrm{eV}$ ), with high and low bandwidth filters removing modes outside the energy ranging from 15 to $30 \mathrm{keV}$. This combined with the ca. $250 \mathrm{~m}$ beamline length provides excellent in-line phase contrast. A $2560 \times 2160$-pixel PCO Edge 5.5 CMOS camera optically coupled to a single crystal CdWO4 scintillator was used to record the projection images. The distance between the sample and the scintillator was optimized to be $\sim 35 \mathrm{~mm}$ to achieve an optimum imaging quality. The final pixel size obtained was $0.81 \mu \mathrm{m}$ for the scans.

During the in situ experiments, each tomographic run includes collecting 720 projections evenly spaced over a $180^{\circ}$ rotation with the exposure time of $0.1 \mathrm{~s}$. For FC, the scans were not recorded continuously due to the limitation of sampling rate relative to the fast cooling rate $(5 \mathrm{~K} / \mathrm{min})$ and two images were acquired at the start and end points of the process, i.e., $270 \mathrm{~K}$ and $250 \mathrm{~K}$, respectively, indicated as pentagons in Figure 3. For the same sampling limitation, there were no scans recorded during the fast heating $(5 \mathrm{~K} / \mathrm{min})$. For the $\mathrm{SC}$, the scans were recorded and pre-processed one by one and the 3D images were reconstructed at $266.8 \mathrm{~K}, 263.4 \mathrm{~K}, 260.8 \mathrm{~K}$, and $250 \mathrm{~K}$ for analysis, as indicated as hexagons in Figure 3. These are referred to as SC0, SC1, SC2, and SC3 samples, respectively. For the ex situ experiments, each tomographic run includes 3601 projections over a $180^{\circ}$ rotation with the same exposure time of $0.1 \mathrm{~s}$ for each projection.

\subsection{Volume Data Reconstruction and Pre-Processing}

The collected 2D radiographs/projections were stacked and converted into sinograms and in which any apparent continuous lines were removed by interpolation to reduce ring artifacts due to imperfections from the detector/camera. The sinograms were then used to reconstruct the volume slices using a filtered back projection (FBP) based algorithm. Because the ice cream samples were relatively low attenuating to the incident $\mathrm{X}$-ray beam, the reconstructed volumes exhibited a relatively high level of noise. Therefore, the 3D volumes need to be filtered before any feature segmentation and quantification can be applied. Due to the microstructural differences in ex situ and in situ experiments, the data processing methods are slightly different.

For the ex situ experiments, a novel image processing strategy and reconstruction algorithm were used to achieve better quality images from the collected data; for details, see References [2,7]. A morphologically based method was used to quickly and robustly reduce the noise in the reconstructed volume of in situ data. First, 3D median filtering $(3 \times 3 \times 3)$ was performed on all the reconstructed volumes. Then the volumes were cleared using a series of morphological operations. Both ex situ and in situ data were then binarized and labeled using global thresholding. All the volumes were subsequently checked visually, and any obvious segmentation imperfections were corrected manually using Avizo 9.4 (FEI Visualization Sciences Group, Mérignac, France).

\subsection{D Based Quantification of Ice Crystal Dimensions}

In the in situ study, an image analysis based quantification methodology of the ice crystal size in the ice cream samples was developed which is similar to the techniques for porous structure characterization for biomedical and geological samples [30]. Depending on the morphology of a porous structure, the pore size distribution can be obtained either by summarizing information of individually labeled components or estimated by measuring the variation of the interpenetrating volumes as a function of effective pore size. Here, as ice crystals appear as interconnected clusters, segmenting them into individual components is not appropriate. Therefore, we developed a method that provides an analysis similar to that of mercury intrusion porosimetry (MIP) to quantify the ice phase size distribution in the samples (see References [31,32]). In the MIP analysis, the pore size distribution within a porous sample can be determined from the cumulative volume of mercury liquid 
that has been forced into the pore space by externally applied high pressure. Here, we used a series of sampling spheres of varying diameter, and the size distribution in the ice crystal phase can be obtained by measuring the cumulative volume of ice crystal that can be reached by different sampling spheres.

The variation in accessible volume was used to estimate the ice crystal (or any segmented phase) size distribution, as follows:

1. A 3D distance map was first created by a Euclidean distance transform from the binarized image.

2. For the current samples, 13 sampling spheres with a diameter equally spaced between $5 \mu \mathrm{m}$ and $40 \mu \mathrm{m}$ were chosen to balance the quantification accuracy and computational expenses.

3. The radius of each sampling sphere (in voxels) was compared to the voxel intensities in the distance map, determining the centers of the spheres of a radius that can be completely placed within the ice phase.

4. A dilation algorithm was then applied to the voxels correlated to the sphere centers, using a spherical kernel of the same radius. The volume after dilation is the volume correlated to the sampling sphere.

5. Step 3-4 were repeated for all the sampling sphere dimensions chosen in step 2, providing a range of reachable volumes corresponding to increasing sphere diameters.

6. The volume fraction was calculated by dividing each volume by the total volume of the ice phase. Then an ice crystal size distribution can be calculated as the differential of the area under the cumulative volume percentage curve.

For the ex situ study, the reconstructed volumes from the data were cropped into a smaller volume, followed by the microstructural quantification in 3D. The three-dimensional rendering of the features, as well as the quantification of the ice crystals, was performed by manually using Avizo 9.4 (FEI Visualization Sciences Group, Mérignac, France). For more details, see References [2,7].

\section{Results and Discussion}

\subsection{In Situ: Microstructural Evolution-2D Images}

First, a tomographic scan was collected at $270 \mathrm{~K}$ prior to the onset of fast cooling. Except for air cells, it was not possible to resolve structural features in the material at this temperature. This indicates that it was above the freezing point of the ice cream composition under investigation and additionally significant supercooling is required before ice crystal nucleation occurs.

Figure 4a,b show representative 2D tomographic image slices recorded after the fast cooling from 270 to $250 \mathrm{~K}$ and Figure 4c,d show representative image slices following the fast heating at $5 \mathrm{~K} / \mathrm{min}$ from 250 to $267 \mathrm{~K}$ and holding at that temperature for $10 \mathrm{~min}$. The main features evident at low magnification in Figure $4 \mathrm{a}, \mathrm{c}$ are the light grey contrast circular features which are low X-ray attenuation air cells introduced by sample handling and imaging. These are embedded in a material with a fine scale microstructure showing grey/white contrast. At higher magnification (Figure $4 b, d$ ), the details of this matrix material's microstructure are revealed. In Figure $4 \mathrm{~b}$, following fast cooling to $250 \mathrm{~K}$, the microstructure comprises a high volume fraction of ice crystals (grey) with a lighter contrast continuous phase surrounding the crystals; the latter is the unfrozen matrix phase comprising a concentrated sucrose solution, fat globules, and solids. The ice crystals have a range of sizes and are apparently lozenge-shaped with dimensions of the order of 5 to $10 \mu \mathrm{m}$, with domains of aligned crystals. In Figure 4d, following fast heating from $250 \mathrm{~K}$ to $267 \mathrm{~K}$, it is clear that the ice crystals occupy a significantly smaller volume fraction than at $250 \mathrm{~K}$. Furthermore, the dimensions of the ice crystals have increased markedly following the fast heating and short, $10 \mathrm{~min}$, holding time at $267 \mathrm{~K}$. The coarsening could be due to factors such as Ostwald ripening and physical agglomeration during heating and holding. In Ostwald ripening, the driving force is the difference in solubility between the polydisperse particles of different curvatures. This solubility difference establishes a concentration gradient between the smaller and the larger particles, which leads to the growth of the larger particles 
at the expense of the smaller ones, the solute being transported through the unfrozen phase. It should also be noted that the volume fraction of air cells could potentially increase due to the photochemical cracking by the X-rays (Figure 4a,c) [33].
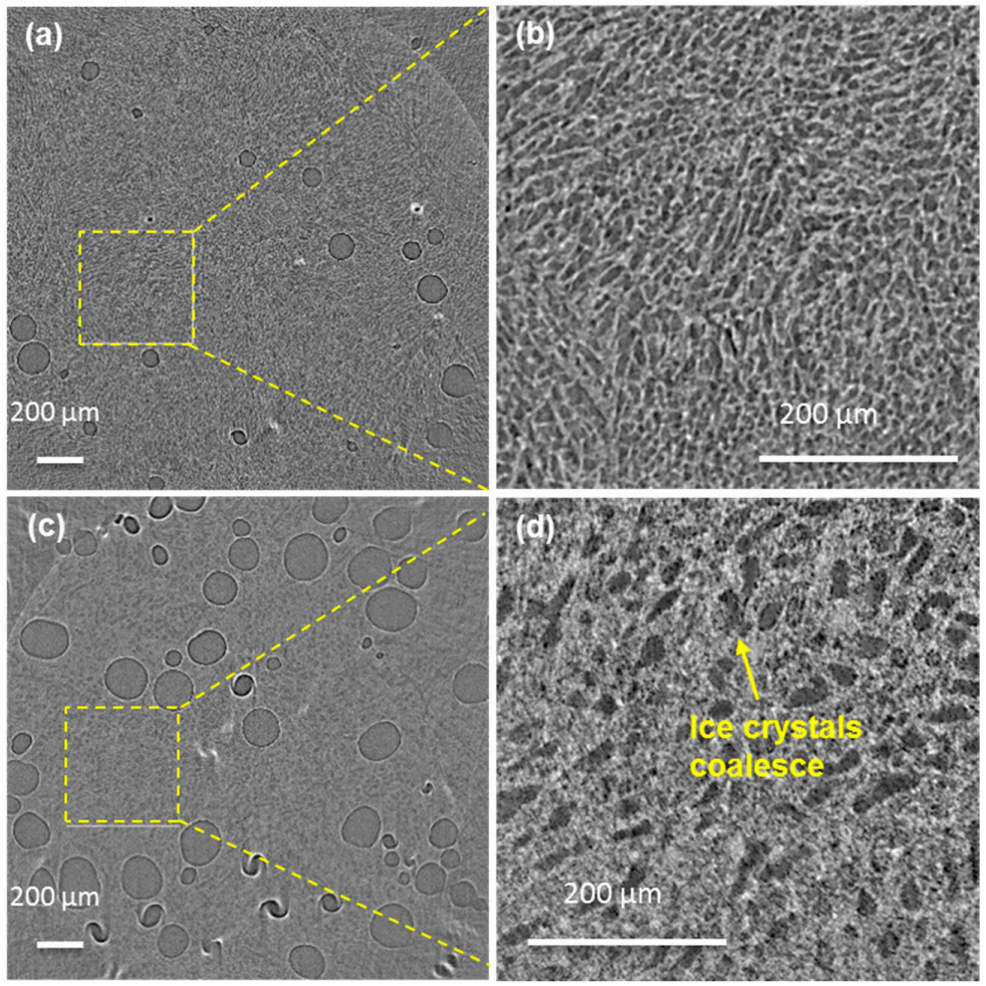

Figure 4. The reconstructed $2 \mathrm{D}$ tomographic slices. (a,b) Following fast cooling (FC) to $250 \mathrm{~K}$. (c,d) Following heating to $266.8 \mathrm{~K}$ and holding for $10 \mathrm{~min}$. In (a), the large circular dark areas with thin brighter boundaries are air cells and the matrix comprises of a dark contrast for the ice crystals and a brighter contrast for the unfrozen material. Zoom-ins of the areas highlighted by yellow squares in $(\mathbf{a}, \mathbf{c})$ are shown in $(\mathbf{b}, \mathbf{d})$ respectively.

Figure 5a-d show the 2D tomographic slices recorded at $266.8 \mathrm{~K}, 263.4 \mathrm{~K}, 260.3 \mathrm{~K}$, and $250 \mathrm{~K}$ respectively during the slow cooling (SC) regime $(0.05 \mathrm{~K} / \mathrm{min})$ following a $10 \mathrm{~min}$ hold at $267 \mathrm{~K}$. During this regime, it is obvious that ice crystals grow in size and the morphologies became more spherical than those at $267 \mathrm{~K}$ supporting the proposed mechanisms of Ostwald ripening and physical agglomeration. Moreover, the ice crystal volume fraction increases significantly and the specific interface area $\left(S_{S}\right)$ which is given by the interfacial area between ice (solid) and unfrozen matrix (liquid), denoted as A, divided by the total enclosed volume of ice (solid), denoted as $\mathrm{V}_{\mathrm{s}}$, i.e., $S_{S}=\frac{A}{V_{s}}$, decreases during slow cooling and solidification (Table 1). There is also evidence, from the morphological features, that some of the ice crystals appear to have coalesced (see coalesced structure highlighted by an arrow in Figure 5d).

Table 1. The total volume fraction and specific interface area $\left(\mathrm{S}_{\mathrm{s}}\right)$ of ice crystals quantified by 3D tomography.

\begin{tabular}{cccc}
\hline Cooling Rate & Temperature (K) & Ice Volume Fraction (\%) & specific Interface Area $\mathbf{( S}_{\mathbf{s}} \mathbf{)}\left(\mathbf{m m}^{\mathbf{- 1}}\right)$ \\
\hline FC & 250.0 & 38 & 599 \\
SC0 & 266.8 & 28 & 301 \\
SC1 & 263.4 & 40 & 247 \\
SC2 & 260.3 & 36 & 233 \\
SC3 & 250.0 & 46 & 193 \\
\hline
\end{tabular}



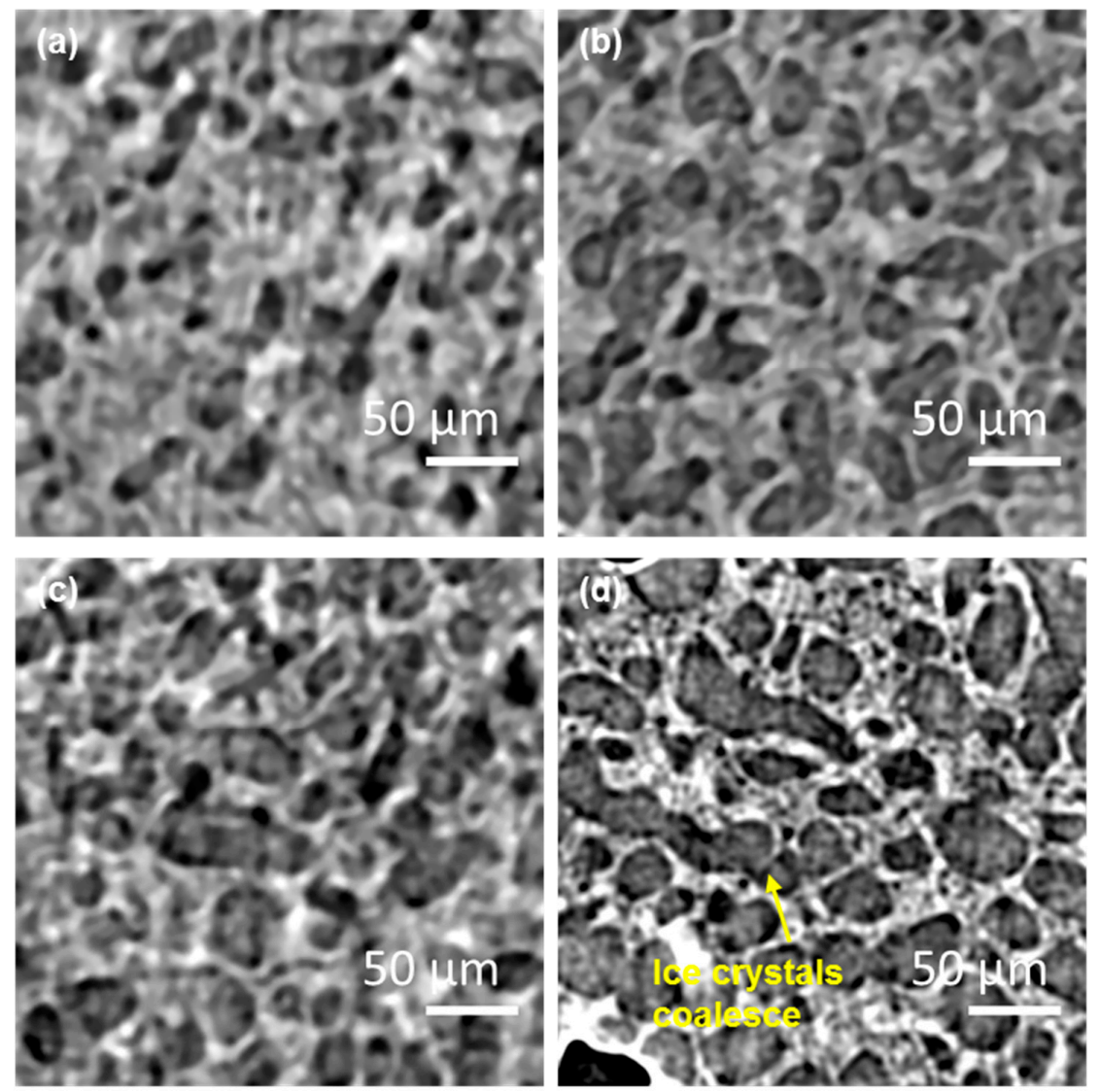

Figure 5. The 2D reconstructed tomographic slice showing the microstructural evolution of ice crystals during the slow cooling regime at the following temperatures: (a) $266.8 \mathrm{~K}$, (b) $263.4 \mathrm{~K}$, (c) $260.8 \mathrm{~K}$ and (d) $250 \mathrm{~K}$. Note, for images taken at $260 \mathrm{~K}$ and above, coarsening occurs during image acquisition, blurring the image.

\subsection{In situ: 3D Microstructural Evolution as a Function of Temperature and Time}

The 3D rendering of ice crystals and un-frozen matrix from representative regions of the same size are shown in Figure 6. In agreement with the 2D observations, the ice crystals are fine after the FC stage (Figure 6a) and after the fast heating and holding (Figure 6b), the small ice crystals have transformed into much larger ones. The ice crystal size continues to increase during the slow cooling period (Figure 6b-e). The color-coded local thickness of the ice crystals in Figure 6a-e allows us to better visualize the increase of the ice crystal thickness during the experiment (see quantification in the next section). The 3D interconnected volume of the unfrozen matrix is shown in Figure $6 \mathrm{f}-\mathrm{j}$. It appears that the wall thickness of the unfrozen matrix tended to increase upon heating (from $250 \mathrm{~K}$ to $267 \mathrm{~K}$ ), whilst the thickness decreases as the temperature falls and the volume fraction of the ice increases in line with Figure 1a. 


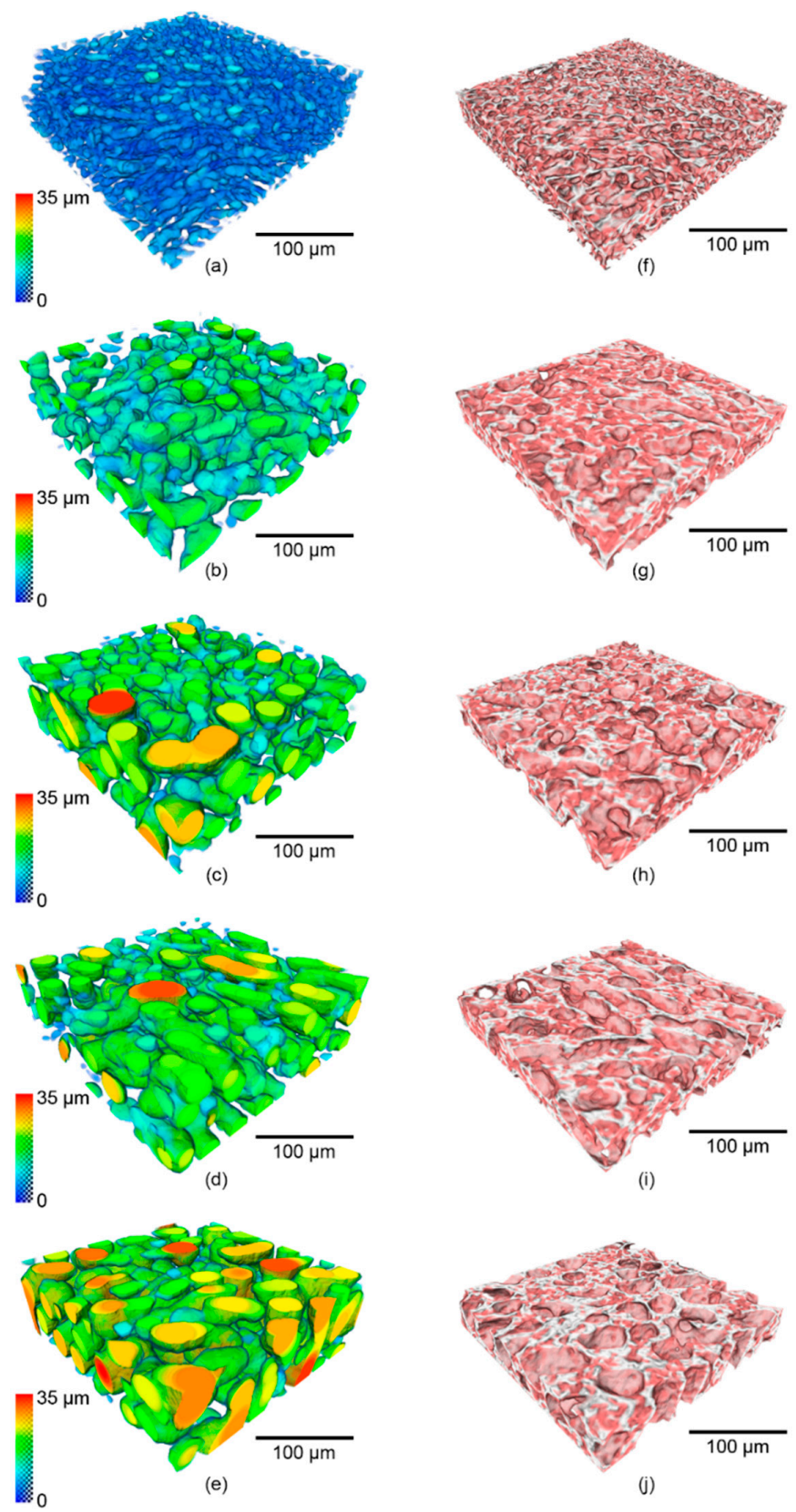

Figure 6. The 3D morphological evolution of representative volumes of $(\mathbf{a}-\mathbf{e})$ ice crystals and $(\mathbf{f}-\mathbf{j})$ the unfrozen matrix during the in situ experiment. $(\mathbf{a}, \mathbf{f})$ show the ice crystals and un-frozen matrix after fast cooling (FC) and holding at $250 \mathrm{~K}$. During the slowing cooling (SC) period, the ice crystals, and un-frozen matrix are shown for the following temperatures: (b,g) $266.8 \mathrm{~K},(\mathbf{c}, \mathbf{h}) 263.4 \mathrm{~K},(\mathbf{d}, \mathbf{i}) 260.8 \mathrm{~K}$, and $(\mathbf{e}, \mathbf{j}) 250 \mathrm{~K}$ respectively. In (a-e), the color of the renderings correlates with the 3D local thickness of the ice crystals.

The size distributions of ice crystals and the unfrozen matrix, obtained from the 3D accessible volume method, are shown in Figure 7. As expected from the 2D tomographic slices (Figures 4 and 5) and the 3D reconstructed volume rendering (Figure 6), after the FC stage the ice crystals were very fine with a modal size of $8.2 \mu \mathrm{m}$ and a range from around 1 to $15 \mu \mathrm{m}$. When the temperature was raised from $250 \mathrm{~K}$ to $267 \mathrm{~K}$ at $5 \mathrm{~K} / \mathrm{min}$ and held for $10 \mathrm{~min}$, the modal value of the size distribution increased to $11.2 \mu \mathrm{m}$. The distribution curve shifted to the right with a wider distribution ranging from 1-26 $\mu \mathrm{m}$, which suggests the melting of smaller ice crystals and the growth of larger crystals at high temperature accompanying an overall decrease in ice volume with the increasing temperature. During 
slow cooling at a rate of $0.05 \mathrm{~K} / \mathrm{min}$, the modal size increased dramatically to $17.2 \mu \mathrm{m}$ at $263.4 \mathrm{~K}$ (SC1) and to $20.2 \mu \mathrm{m}$ at $260.8 \mathrm{~K}$ (SC2). Once the temperature had dropped below $263 \mathrm{~K}$, the changes in size distribution at this cooling rate were not significant, which indicates that continued cooling below $263 \mathrm{~K}$ does not have a significant influence on the size of ice crystals over the timescale of the present experiments. It is presumably due to the slow molecular thermal diffusion at low temperatures, resulting in a reduced rate of coarsening.

In a complementary manner, the effects of the thermal history on the unfrozen matrix were also quantified. Figure $7 \mathrm{~b}$ shows the size distribution of the unfrozen matrix at different temperatures, quantified using the same method as that employed for ice crystals (see Section 2.5). The unfrozen matrix is a complex 3D network that maintains the integrity of the ice cream structure. The 3D volume rendering in Figure $6 \mathrm{f}-\mathrm{j}$ show that the unfrozen matrix appeared thicker between the ice crystals during the heating regime, whilst it became thinner as the sample cooled down from $267 \mathrm{~K}$ to $250 \mathrm{~K}$, due to the melting of the ice crystals during the heating and recrystallization during cooling.

These qualitative observations are supported by the numerical data. The unfrozen matrix at $267 \mathrm{~K}(20.2 \mu \mathrm{m})$ after heating is much greater in thickness than that measured at $250 \mathrm{~K}(8.2 \mu \mathrm{m})$, which supports the idea that small crystals were melting into the unfrozen matrix as the temperature increased. During the SC regime, a trend of decreasing size of the unfrozen matrix is observed when the temperature of the sample was slowly cooled down to $250 \mathrm{~K}$. This is presumably due to the growth increasing volume fraction of ice crystals, and is consistent with our quantification for the overall increased size of the ice crystal.
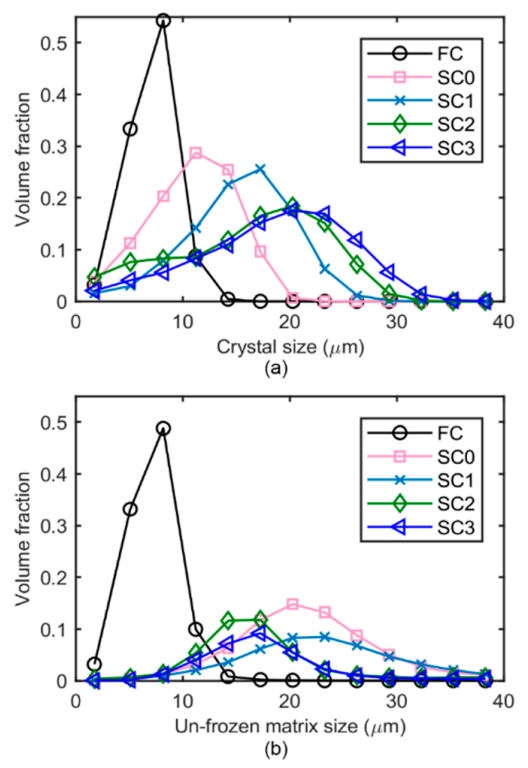

Figure 7. The size distributions of (a) the ice crystals and (b) the unfrozen matrix in the ice cream sample after fast cooling to $250 \mathrm{~K}$ (FC), and then after the fast reheating and holding process at $266.8 \mathrm{~K}$ (SC0), and during the slow cooling process at $263.4 \mathrm{~K}$ (SC1), $260.8 \mathrm{~K}$ (SC2), and $250 \mathrm{~K}$ (SC3), respectively.

The morphological changes of ice crystals are accompanied by changes in the total ice fraction and specific interface area $\left(\mathrm{S}_{\mathrm{s}}\right)$ as revealed in $\mathrm{mm}^{-1}$ when cooled down to $250 \mathrm{~K}$.

Table 1 . Both the volume fraction and specific interface area $\left(\mathrm{S}_{\mathrm{s}}\right)$ of ice crystals decreased during heating and holding, which supports the observation of the partial melting and coarsening of ice crystals. During this period, the needle-shaped ice crystals at $250 \mathrm{~K}$ became more spherical after the heating regime (clearly to minimize the interfacial free energy). The fraction of ice decreased significantly from $38 \%$ at $250 \mathrm{~K}$ to $28 \% 267 \mathrm{~K}$, which is consistent with the melting phenomenon while heating. In the SC regime, we noted that the increase of the ice volume fraction with freezing is not 
completely monotonic. One possible reason for this is the relative movement of the entire volume during cooling, which might change the features that are measured.

The $S_{\mathrm{s}}$ of ice crystals first decreased dramatically from 599 to $301 \mathrm{~mm}^{-1}$ during the fast heating and holding period. However, the morphology of the ice crystals showed only small changes during the SC regime, as indicated by the average $S_{\mathrm{s}}$ decreasing from $301 \mathrm{~mm}^{-1}$ at $267 \mathrm{~K}$ to $247 \mathrm{~mm}^{-1}$ at $263 \mathrm{~K}$, and then continuously decreased to $193 \mathrm{~mm}^{-1}$ when cooled down to $250 \mathrm{~K}$.

\subsection{Ex Situ: Microstructural Evolution of Ice Crystals Following Long-Term Thermal Cycling}

Apart from the dynamic evolution mechanism of the individual features in ice cream which were elucidated in the in situ study, an examination of the microstructural evolution over long timescales (days/weeks) was also performed. The results are summarized in Figure 8 and reported in more detail in a previous paper [7]. After the thermal cycling from 258 to $268 \mathrm{~K}$ for 7 days, the size of ice crystals increased from a modal value of $45 \mu \mathrm{m}$ in the C0 sample to a modal value of $85 \mu \mathrm{m}$ in the C7 sample leading to coarsened ice structures and an ice cream that is likely to have a less desirable perception of texture for consumers. The size of the ice crystals was found to continuously grow even after 14-day long cycles. However, the rate of growth dramatically decreased after 7 cycles (7-day sample), with the size of ice crystals increasing only by $\sim 10 \mu \mathrm{m}$ from sample $\mathrm{C} 7$ to sample $\mathrm{C} 14$. It is possible that most of the surfaces of the ice crystals following 7 cycles are close to the size of the walls between the air cells. Therefore, air cells act as diffusion barriers, reducing Ostwald growth to being controlled by one-dimensional diffusion only in the plane of the wall. To demonstrate the morphological evolution in detail, a representative 3D rendering of ice crystals from the $\mathrm{SCT}$ data is superimposed in Figure 8.

Compared with the ex situ study, the size distribution obtained following the FC stage of the in situ work has a much smaller modal value of $8.2 \mu \mathrm{m}$. Such a fine scale microstructure is possible due to the fast cooling from the ice cream mix (liquid), which is different from the ex situ coarsened ice cream sample which was being "thermally abused" for a number of cycles between 258 and $268 \mathrm{~K}$, i.e., the maximum temperature was well below the temperature of zero ice fraction (Figure 1a).

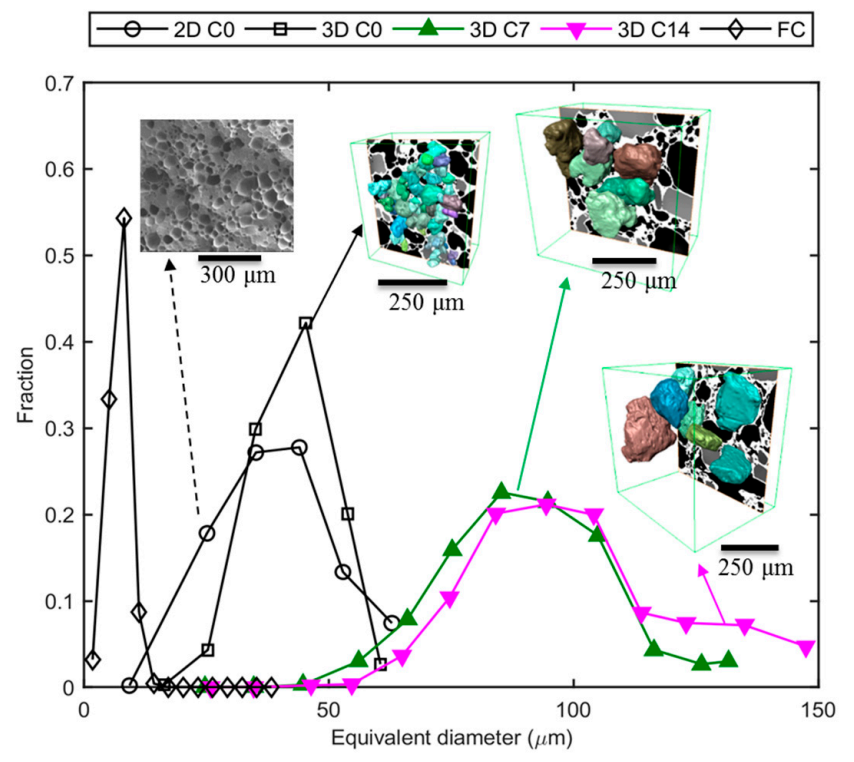

Figure 8. The size distributions of ice crystals in the ice cream samples following the FC stage from the in situ experiment, and C0, C7, C14 samples from the ex situ experiment. For the ex situ experiments, the morphology of the ice crystals is shown in the inserts as 3D color renderings of individual ice crystals. Additional data are taken from Reference [7]. 


\section{Conclusions}

In the present study, we applied in situ and operando time-resolved synchrotron tomography in a bespoke cold stage to quantify the fast evolution of the different microstructural phases in ice cream during processing, including ice crystals and the unfrozen matrix. To capture the long-term microstructural evolution during storage, we used an ex situ sCT methodology.

The in situ experimental results in this study reveal that the coarsening of ice crystals was due to both Ostwald ripening and physical agglomeration during heating and cooling. This change in the ice crystals size and morphology strongly influences our sensory perception of ice cream's taste. During the subsequent storage, we demonstrate that fluctuations in storage temperature can cause a partial-melting and recrystallization process, increasing the rate of coarsening. These processes were quantified, providing valuable data to both inform and validate models of the behavior of soft-solids.

Author Contributions: Conceptualization, P.D.L., E.G., P.S., G.V.D., J.B.; Methodology, E.G., J.M., P.R., D.S.E., P.D.L., P.S., J.B.; Formal Analysis, J.M., E.G.; Writing-Original Draft Preparation, J.M., E.G., P.D.L., D.G.M.; Writing-Review \& Editing, All.

Funding: This work was financially supported by Unilever R\&D (Colworth, UK) and by the EPSRC-UK (EP/I02249X/1, EP/J010456/1 and EP/M009688/1).

Acknowledgments: The authors acknowledge the use of the facility access in Diamond Light Source (MT12194, MT12195, MT12616 and MT17609) and Research Complex at Harwell. The authors also thank I13 staff of Diamond Light Source (especially Cipiccia) and group members for technical support.

Conflicts of Interest: The authors declare no conflict of interest.

\section{References}

1. Clarke, C. The Science of Ice Cream; Royal Society of Chemistry: London, UK, 2015.

2. Guo, E.; Kazantsev, D.; Mo, J.; Bent, J.; Van Dalen, G.; Schuetz, P.; Rockett, P.; StJohn, D.; Lee, P.D. Revealing the microstructural stability of a three-phase soft solid (ice cream) by $4 \mathrm{D}$ synchrotron X-ray tomography. J. Food Eng. 2018, 237, 204-214. [CrossRef]

3. Clarke, C. The physics of Ice Cream. Phys. Educ. 2003, 38, 248-253. [CrossRef]

4. Cook, K.L.K.; Hartel, R.W. Effect of freezing temperature and warming rate on dendrite break-up when freezing ice cream mix. Int. Dairy J. 2011, 21, 447-453. [CrossRef]

5. Chang, Y.; Hartel, R.W. Measurement of air cell distributions in dairy foams. Int. Dairy J. 2002, 12, 463-472. [CrossRef]

6. Sofjan, R.P.; Hartel, R.W. Effects of overrun on structural and physical characteristics of ice cream. Int. Dairy J. 2004, 14, 255-262. [CrossRef]

7. Guo, E.Y.; Zeng, G.; Kazantsev, D.; Rockett, P.; Bent, J.; Kirkland, M.; Van Dalen, G.; Eastwood, D.S.; StJohn, D.; Lee, P.D. Synchrotron X-ray tomographic quantification of microstructural evolution in ice cream-A multiphase soft solid. Rsc. Adv. 2017, 7, 15561-15573. [CrossRef]

8. Goff, H.D.; Verespej, E.; Smith, A.K. A study of fat and air structures in ice cream. Int. Dairy J. 1999, 9, 817-829. [CrossRef]

9. Cook, K.L.K.; Hartel, R.W. Mechanisms of Ice Crystallization in Ice Cream Production. Compr. Rev. Food Sci. Food Saf. 2010, 9, 213-222. [CrossRef]

10. Flemings, M.C.; Riek, R.; Young, K. Rheocasting. Mater. Sci. Eng. 1976, 25, 103-117. [CrossRef]

11. Van Dalen, G. A study of bubbles in foods by X-ray microtomography and image analysis. Microsc. Anal. 2012, 26, S8-S12.

12. Eisner, M.D.; Wildmoser, H.; Windhab, E.J. Air cell microstructuring in a high viscous ice cream matrix. Colloids Surf. A: Physicochem. Eng. Asp. 2005, 263, 390-399. [CrossRef]

13. Méndez-Velasco, C.; Goff, H.D. Fat structure in ice cream: A study on the types of fat interactions. Food Hydrocoll. 2012, 29, 152-159. [CrossRef]

14. Chang, Y.; Hartel, R. Stability of air cells in ice cream during hardening and storage. J. Food Eng. 2002, 55, 59-70. [CrossRef]

15. Chang, Y.; Hartel, R.W. Development of air cells in a batch ice cream freezer. J. Food Eng. 2002, 55, 71-78. [CrossRef] 
16. Caillet, A.; Cogné, C.; Andrieu, J.; Laurent, P.; Rivoire, A. Characterization of ice cream structure by direct optical microscopy. Influence of freezing parameters. LWT-Food Sci. Technol. 2003, 36, 743-749. [CrossRef]

17. Cheng, J.; Ma, Y.; Li, X.; Yan, T.; Cui, J. Effects of milk protein-polysaccharide interactions on the stability of ice cream mix model systems. Food Hydrocoll. 2015, 45, 327-336. [CrossRef]

18. Pinzer, B.R.; Medebach, A.; Limbach, H.J.; Dubois, C.; Stampanoni, M.; Schneebeli, M. 3D-characterization of three-phase systems using X-ray tomography: Tracking the microstructural evolution in ice cream. Soft Matter 2012, 8, 4584-4594. [CrossRef]

19. Vicent, V.; Verboven, P.; Ndoye, F.T.; Alvarez, G.; Nicolai, B. A new method developed to characterize the 3D microstructure of frozen apple using X-ray micro-CT. J. Food Eng. 2017, 212, 154-164. [CrossRef]

20. Lee, P.; Hunt, J. Hydrogen porosity in directional solidified aluminium-copper alloys: In situ observation. Acta Mater. 1997, 45, 4155-4169. [CrossRef]

21. Leung, C.L.A.; Marussi, S.; Atwood, R.C.; Towrie, M.; Withers, P.J.; Lee, P.D. In situ X-ray imaging of defect and molten pool dynamics in laser additive manufacturing. Nat. Commun. 2018, 9, 1355. [CrossRef] [PubMed]

22. Stock, S. Recent advances in X-ray microtomography applied to materials. Int. Mater. Rev. 2008, 53, $129-181$. [CrossRef]

23. Maire, E.; Withers, P.J. Quantitative X-ray tomography. Int. Mater. Rev. 2014, 59, 1-43. [CrossRef]

24. Bhreasail, Á.N.; Lee, P.; O'Sullivan, C.; Fenton, C.; Hamilton, R.; Rockett, P.; Connolley, T. In-Situ Observation of Cracks in Frozen Soil using Synchrotron Tomography. Permafr. Periglac. Process. 2012, 23, 170-176. [CrossRef]

25. Figueroa Pilz, F.; Dowey, P.J.; Fauchille, A.L.; Courtois, L.; Bay, B.; Ma, L.; Taylor, T.G.; Mecklenburgh, J.; Lee, P. Synchrotron tomographic quantification of strain and fracture during simulated thermal maturation of an organic-rich shale, UK Kimmeridge Clay. J. Geophys. Res. Solid Earth 2017, 122, 2553-2564. [CrossRef]

26. Polacci, M.; Arzilli, F.; La Spina, G.; Le Gall, N.; Cai, B.; Hartley, M.E.; Genova, D.D.; Vo, N.T.; Nonni, S.; Atwood, R.C.; et al. Crystallisation in basaltic magmas revealed via in situ $4 \mathrm{D}$ synchrotron X-ray microtomography. Sci. Rep. 2018, 8, 8377-8383. [CrossRef] [PubMed]

27. Reinke, S.K.; Wilde, F.; Kozhar, S.; Beckmann, F.; Vieira, J.; Heinrich, S.; Palzer, S. Synchrotron X-ray microtomography reveals interior microstructure of multicomponent food materials such as chocolate. J. Food. Eng. 2016, 174, 37-46. [CrossRef]

28. Kareh, K.M.; Lee, P.D.; Atwood, R.C.; Connolley, T.; Gourlay, C.M. Revealing the micromechanisms behind semi-solid metal deformation with time-resolved X-ray tomography. Nat. Commun. 2014, 5, 4464. [CrossRef] [PubMed]

29. Karagadde, S.; Lee, P.D.; Cai, B.; Fife, J.L.; Azeem, M.A.; Kareh, K.M.; Puncreobutr, C.; Puncreobutr, D.; Puncreobutr, T.; Puncreobutr, R.C. Transgranular liquation cracking of grains in the semi-solid state. Nat. Commun. 2015, 6, 8300. [CrossRef] [PubMed]

30. Wu, Z.Y.; Hill, R.G.; Yue, S.; Nightingale, D.; Lee, P.D.; Jones, J.R. Melt-derived bioactive glass scaffolds produced by a gel-cast foaming technique. Acta Biomater. 2011, 7, 1807-1816. [CrossRef] [PubMed]

31. Atwood, R.C.; Jones, J.R.; Lee, P.D.; Hench, L.L. Analysis of pore interconnectivity in bioactive glass foams using X-ray microtomography. Scr. Mater. 2004, 51, 1029-1033. [CrossRef]

32. Yue, S.; Lee, P.D.; Poologasundarampillai, G.; Jones, J.R. Evaluation of 3-D bioactive glass scaffolds dissolution in a perfusion flow system with X-ray microtomography. Acta Biomater. 2011, 7, 2637-2643. [CrossRef] [PubMed]

33. Mao, W.L.; Mao, H.K.; Meng, Y.; Eng, P.J.; Hu, M.Y.; Chow, P.; Cai, Y.Q.; Shu, J.; Hemley, R.J. X-ray-induced dissociation of $\mathrm{H}_{2} \mathrm{O}$ and formation of an O-2-H-2 alloy at high pressure. Science 2006, 314, 636-638. [CrossRef] [PubMed]

(C) 2018 by the authors. Licensee MDPI, Basel, Switzerland. This article is an open access article distributed under the terms and conditions of the Creative Commons Attribution (CC BY) license (http://creativecommons.org/licenses/by/4.0/). 